\title{
MJFA MALAYSIAN JUURNAL OF

\section{Separation and purification of triglyceride from nyamplung (Calophyllum inophyllum) seed oil as biodiesel feedstock by using continuous countercurrent extraction}

\author{
Setiyo Gunawan*, Hakun Wirawasista Aparamarta, Fadlilatul Taufany, Arief Prayogo, Shelma \\ Hajar Anugrah Putri, Christian Julius Wijaya
}

Department of Chemical Engineering, Institut Teknologi Sepuluh Nopember, Surabaya 60111, Indonesia

* Corresponding author: gunawan@chem-eng.its.ac.id

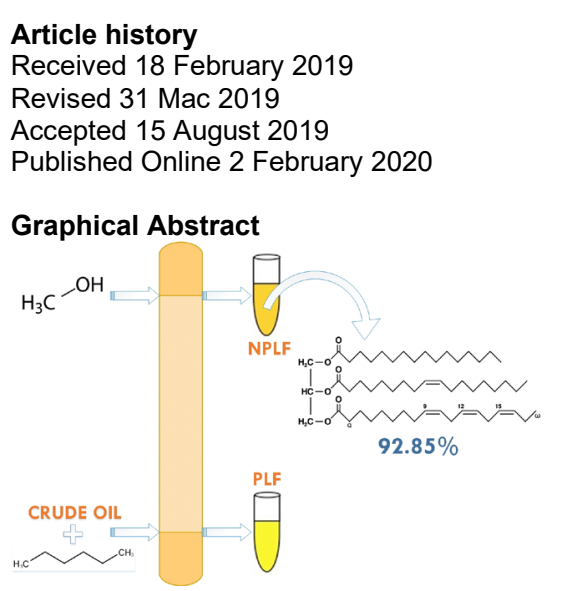

\begin{abstract}
Calophyllum inophyllum or commonly called nyamplung in Indonesia has the potential to be used as a biodiesel feedstock due to its high oil content. The purpose of this study was to determine the effect of feed flowrate and solvent to oil mass ratio on triglycerides (TAG) and free fatty acid (FFA) contents in non-polar lipid fraction (NPLF) of $C$. inophyllum seed oil by using continuous counter-current extraction. The contents of TAG and FFA in NPLF of $C$. inophyllum seed oil each sample points in continuous countercurrent extraction equipment. It was expected that the TAG became purer and suitable for biodiesel purpose. Various factors applied in this study were the effect of solvent to oil mass ratio and the effect of n-hexane + oil to methanol feed flowrate in liter per hour. Crude C. inophyllum seed oil contained $63.91 \%$ TAG, $15.76 \%$ FFA, $12.25 \%$ monoglycerides (MAG), dan $4.66 \%$ diglycerides (DAG). Separation and purification of TAG were carried out by using a packed column with the principle of countercurrent flow using n-hexane and methanol technical grade as solvents. The product of extraction analyzed TAG content qualitatively by using TLC and quantitatively using HT-GC, while NPLF from each sample points were analyzed using HT-GC. The optimum results were obtained by using a solvent to oil mass ratio of $6(w: w)$ and (n-hexane + oil) to methanol feed flowrate of $6: 15(\mathrm{~L} / \mathrm{h}: \mathrm{L} / \mathrm{h})$ with $92.85 \%$ content of TAG, $2.19 \%$ content of FFA and $74.79 \%$ yield of NPLF.
\end{abstract}

Keywords: Biodiesel, Calophyllum inophyllum, continuous countercurrent extraction, triglycerides

\section{INTRODUCTION}

Nyamplung plant (Calophyllum inophyllum L.) is a mangrove plant that has a high value because the stems, leaves, flowers, seeds, and sap from this plant can produce a wide range of valuable products. Nyamplung plants are known as plants that produce oils that have the potential to be used as biodiesel. C. inophyllum oil is becoming an important biodiesel feedstock. This is because $C$. inophyllum has a high oil content (40-73\%) and yield (4.680 kg oil per ha) whereas palm has an oil content of $42 \%$ and yield of $5.000 \mathrm{~kg}$ oil per ha (Gunawan et al., 2018; Singh \& Singh, 2010).

In addition to the seeds of nyamplung plants that can be used as a source of oil, the leaves of this plant also serve to treat various diseases, such as irritation of the eyes, migraines, and vertigo (Susanto et al., 2017). This tree wood can be used as a raw material for making board shelter, ship construction materials, and furniture. The roots of this plant also serve to keep the coastal areas from abrasion (Ling et al., 2009). Moreover, they offer protection against waves, winds, storms, and tsunamis.

Liquid-liquid extraction is a method used to separate targeted substances that are still mixed with other substances (impurities) of a liquid solution (feed liquid) by contact with another insoluble liquid (solvent). Targeted substances are separated based on their different solubilities. The solvent dissolves certain components of the feed liquid
(Seader \& Henley, 2006). Equipment for liquid-liquid extraction can be classified into two main categories, batch and continuous processes. The first classification is where mixed liquids and then the insoluble phases to be separated as practiced by Aparamarta et al. (2016). The second classification is where the continuous countercurrent contact exists between the insoluble phases. One of the equipment for continuous countercurrent extraction is packed tower, where the heavy liquid fraction enters the column or tower through the top of the column and the light fraction through the bottom of the column. Both liquids are contacted through packing, subsequently light fluid out through the upper end of the column and heavy liquid out through the bottom column (Treybal, 1951). In the column of liquid-liquid extraction, mass transfer areas are not dependent on the surface packing, but it depends on the drop phase stuck in the tower. Packing is used to increase the length of the flow path thus increasing the residence time of phase down (Rauber, 2004).

The components contained in the extraction of $C$. inophyllum seed oil are triglycerides (TAG), diglycerides (DAG), monoglycerides (MAG), and free fatty acids (FFA). Non-polar lipid fraction (NPLF) of C. inophyllum seed oil with $98.53 \%$ TAG and $0.35 \%$ FFA can be obtained from liquid-liquid extraction by using batch-wise solvent extraction which has been done by Aparamarta et al. (2016). This method is time-consuming and has a low capacity of production as it is used in a laboratory scale. Therefore, the objective of this study was to 
separate and to purify TAG from $C$. inophyllum seed oil with fast processing time, high oil yield, high purity, higher capacity of production, and to confirm the possibility of being biodiesel feedstock.

\section{EXPERIMENTAL}

\section{Materials}

Crude C. inophyllum seed oil was obtained from Koperasi Jarak Tani Lestari (Cilacap, Central Java, Indonesia). Thin-layer chromatography (TLC) aluminum plates (general purpose, $20 \mathrm{~cm} \times 20$ $\mathrm{cm}$, particle size: $250 \mu \mathrm{m}$ ) were purchased from Merck (Darmstadt, Germany). Standard vegetable oil, reagents, and solvents were obtained from commercial sources.

\section{Continuous countercurrent extraction}

In this work, continuous countercurrent extraction was performed using packed extraction column with dimensions of $166 \mathrm{~cm}$ height, 4 $\mathrm{cm}$ diameter, and 1.7 liters volume, containing a raschig ring glass pack with 0.3 inch diameter, 1 inch long, and a bulk density of $0.6 \mathrm{~g} / \mathrm{cm}^{3}$. This instrument consists of six sample points with $17.5 \mathrm{~cm}$ distance between them that serve as fluid mixed outflows.and can be used to evaluate the optimal height of the extraction column.

The flowrate was adjusted using a speed regulator and rotameter. Rotameter with a capacity of $6-100 \mathrm{~L} / \mathrm{h}$ consists of PVC tubes and an indicator. The flowrate in this study was also influenced by pumps. The pumps used were two reciprocating fuel pumps with a capacity of 1300 cc $(1.3 \mathrm{~L} / \mathrm{min})$. To minimize and adjust the flowrate with the specified variable, this instrument was equipped with an adjustable bypass system using the globe valve.

The continuous countercurrent extraction process was begun by dissolving crude $C$. inophyllum seed oil with n-hexane by certain mass ratio according to that variable specified to be streamed through the bottom column, while methanol flowed through the top of the column. The solvent to oil mass ratios were varied by $4: 1,5: 1,6: 1$, and $7: 1$. The scheme of continuous countercurrent extraction process can be seen in Fig. 1. Mixed Crude C. inophyllum seed oil and n-hexane from the lower stream were contacted maximally with methanol as the continuous phase of the upper stream at the packing area that causes polar components, such as free fatty acid, dissolved and diffused into methanol solvent, down to the bottom column due to heavier density. The n-hexane + oil to methanol feed flowrates were varied by $6: 12.5$, 6:15, and 6:20. Conversely, non-polar components, such as triglycerides, was dissolved in the n-hexane solvent and rises to the top of the column due to a lighter density. Before taking samples either at the sample point, raffinate, or extract, it was crucial to ensure that the process was already running in a steady state by following the outflow flowrate approach (everyone minute and 2-3 times of sampling). The steady state was indicated by the steady outflow flowrates. The extract and raffinate were flowed out through the bottom column and the top column, respectively. The sampling and the analyses were done in three replications.

\section{Thin layer chromatography (TLC) analysis}

TLC plate was used in the qualitative analyses of TAG content in C. inophyllum seed oil. The sample was first dripped into TLC plate before it was immersed in a mobile phase with hexane:ethyl acetate:acetic acid content of 90:10:1 (v/v/v) (Gunawan et al., 2006). During immersion, the mobile phase was not allowed to exceed the area specified on the TLC plate. The immersion step was carried out in a tightly sealed bottle and TLC plate was dried at room temperature. UV lamp at $264 \mathrm{~nm}$ was used to visualize the TLC plate.

\section{High-temperature gas chromatography (HT-GC) analysis}

The content of TAG and FFA in the NPLF of $C$. inophyllum seed oil was analyzed by using gas chromatography equipped with a Flame Ionization Detector (FID). Separation was carried out with DB-5HT (5 $\%$-phenyl) -methylpolysiloxane non-polar column ( $15 \mathrm{~m}$ x $0.32 \mathrm{~mm}$ i.d; with a film thickness of $0.1 \mu \mathrm{m})$. The injector and detector temperature were adjusted at $370{ }^{\circ} \mathrm{C}$. The column temperature started at $80{ }^{\circ} \mathrm{C}$ increased to $305^{\circ} \mathrm{C}$ at a rate of $15^{\circ} \mathrm{C} /$ minute, then raised to $335^{\circ} \mathrm{C}$ at a rate of $5{ }^{\circ} \mathrm{C} /$ minute and was kept at $335^{\circ} \mathrm{C}$ for 5 minutes. Furthermore, the column temperature was increased to $365{ }^{\circ} \mathrm{C}$ at a rate of $15{ }^{\circ} \mathrm{C} /$ minute. Nitrogen was used as a carrier gas with a split ratio of 1:50 and had a linear rate of $30 \mathrm{~cm} / \mathrm{s}$ at $80{ }^{\circ} \mathrm{C}$. This analysis used external standards for analyzing the FFA, MAG, DAG, and TAG contents, where the standards were used to identify the calibration curve, not injected in the sample analysis. A sample of $20 \mathrm{mg}$ was dissolved in 1 $\mathrm{mL}$ ethyl acetate, and $1 \mu \mathrm{L}$ of the sample was taken and injected into the GC (Gunawan et al., 2008).

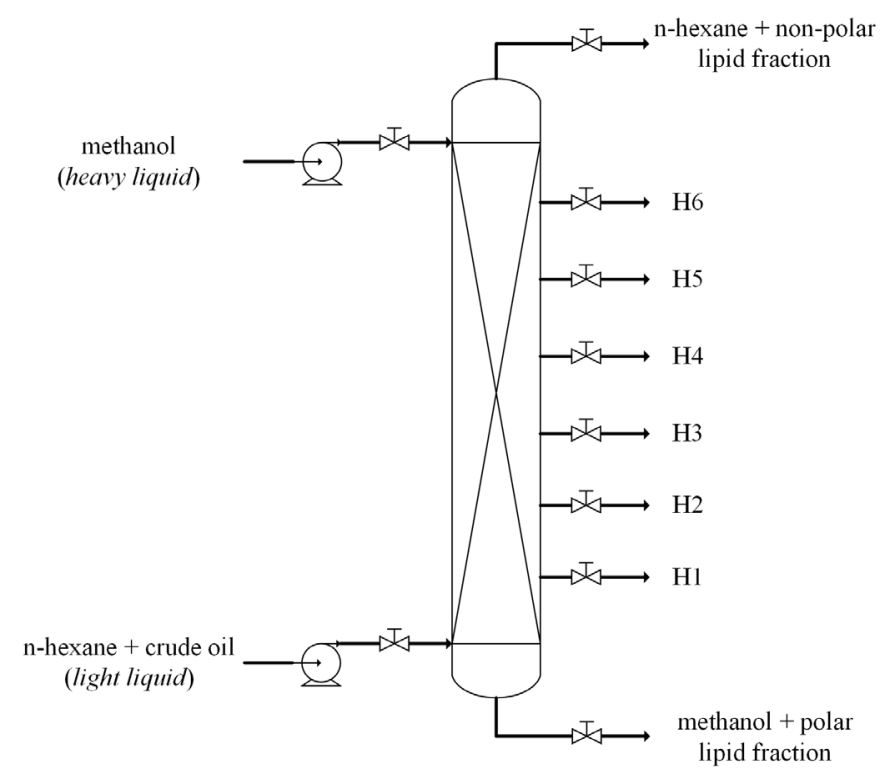

Fig. 1 Scheme of continuous countercurrent extraction process.

\section{RESULTS AND DISCUSSION}

\section{Crude seed oil extraction}

Crude $C$. inophyllum seed oil has various contents based on the geographical location and the climate in which it grows (Atabani et al., 2013). TAG content was investigated to be the highest content of crude C. inophyllum seed oil at $63.91 \%$, followed by $4.66 \%$ of DAG, 12.25 $\%$ of MAG, and $15.76 \%$ of FFA. The other $3.42 \%$ consists of bioactive compounds, such as wax, coumarins, phytosterols, calophyllolides, hydrocarbons, and gum.

Fig. 2 shows the qualitative and quantitative results by using TLC and HT-GC analyses. In the crude oil, the TAG content is actually the highest content as shown in the HT-GC chromatogram. The peak area of the TAG content is larger than the other contents. The TAG content is the one that indicates the suitability of a natural resource as the biodiesel feedstock. As the high TAG content shown in the nyampung seed oil, it proves that nyamplung seed oil has a high potential for biodiesel feedstock.

TAG content reported in previous works was $76.70 \%$ (Hathurusingha et al., 2011) and 78.30\% (Aparamarta et al., 2016). These were higher than that of investigated in this study.

\section{Continuous countercurrent extraction}

Methanol and n-hexane solvents were chosen based on their polarity index, where methanol with a polarity index of 5.1 was considered as a rather polar solvent and n-hexane with a polarity index of 0 which was a non-polar solvent (Sadek, 2002). The solubility of nhexane in methanol was used to be the basis of flowrate ratio selection for the extraction process. The solubility of n-hexane in methanol at 25 ${ }^{\circ} \mathrm{C}$ is $60.4 \mathrm{~g}(39.86 \mathrm{~mL}$ ) of $\mathrm{n}$-hexane per $100 \mathrm{~mL}$ of methanol (Kiser et al., 1955). Therefore, the minimum flowrate ratio of $\mathrm{n}$-hexane and methanol was $1: 2.5$. The higher flowrate ratio makes some part of both solutions are not dissolve each other. It can reduce the contact of both solutions so that the mass transfer of the polar lipid fraction to methanol solution was inhibited.

Filling a packed column with a volume of $1.7 \mathrm{~L}$ until overflow took different time for each combined factor in around 2 to $4 \mathrm{~min}$. The layers formed at the upper zone, lower zone, and sample points were then 
separated. Next, evaporation was done by using rotary vacuum evaporator to separate the NPLF and PLF. The crude $C$. inophyllum seed oil was in the form of dark green liquid, the PLF was semi-solid and dark green, whereas the NPLF was obtained in the form of yellow liquid. This study continued with qualitative analyses using the TLC plate and quantitative analyses using HT-GC device to investigate the content of the separated substances.

The components of $C$. inophyllum seed oil can be separated based on their differences in polarity by TLC analysis. In this study, TAG was found as the most non-polar component. The previous work on soybean oil deodorizer distillate has reported similar observed TLC spots, which showed the presence of free phytosterols, FFA, DAG, tocopherols, TAG, fatty acids stearyl esters, and squalene (Gunawan et al., 2006). Finally, TAG and FFA contents were chosen as the indicators for the effective and significant separation of NPLF from crude $C$. inophyllum seed oil at the raffinate. Aparamarta et al. (2016) reported that peak of ethyl acetate appeared at retention time of 0.5 to 2.5 minutes, peak of FFA at 7.5 to 10 minutes, peak of MAG at 12.25 to 15 minutes, peak of DAG at 16.5 to 18.5 minutes, and peak of TAG at 22 to 26.5 minutes, based on the responses of HT-GC device.

HT-GC analysis was used to analyze the FFA, MAG, DAG, and TAG contents quantitatively. Based on the retention time described by Aparamarta et al. (2016), the crude oil contains the entire composition detected in this analysis. The PLF only contains FFA and MAG as the polar component, while the NPLF contains mostly TAG which is the most non-polar component. The DAG has polarity in the middle of the methanol and n-hexane polarity; hence it is present in both solvents. This causes the polar lipid fraction to be detected in NPLF and vice versa by using qualitative analysis (TLC).

In TLC analysis, the crude oil contains polar lipid fraction as shown by the bold track from the starting point and the non-polar lipid fraction as shown by the hazy block in the highest position (Fig. 2A). The nonpolar lipid fraction presents in the highest amount in NPLF which is proven by the change of the bold track to hazy track. It means the polar lipid fraction was reduced because of the methanol extraction. Whereas, the PLF as the extraction result only contains the polar lipid fraction which is evidenced by the non-existence of the hazy block (TAG compounds) in the highest position.

There were two various factors which was applied in this study: (A) the effect of solvent to oil mass ratio at levels of 4, 5, 6, and 7, and (B) the effect of (n-hexane + oil) to methanol feed flowrate $(\mathrm{L} / \mathrm{h})$ at levels of $6: 12.5,6: 15$, and $6: 20$. These two variables were chosen because it was predicted to be the most significant factor. This prediction was made based from the preliminary experiment. The NPLF and PLF was not separated when higher values of both factors were employed.

\section{Effects of solvent to oil mass ratio}

The most significant result was obtained by using a solvent to oil mass ratio of 6 , as it shows the highest content of TAG and the lowest content of FFA. The total solvent used is more than the oil mass because of the chances of TAG extracted through contact with the solvent, expanded by improving the amount of solvent, which is stopped after the equilibrium is reached (Tan et al., 2011). TAG content was investigated increase and FFA content decreased significantly as a solvent to oil mass ratio was increased from 4 to 6 . In contrast, as this ratio was increased from 6 to 7 , TAG content was investigated decrease and FFA content increased, as shown in Fig. 3. Except for the n-hexane + oil to methanol feed flowrate at a level of $6: 20$, in which the result obtained was fluctuating. It can be caused by the equilibrium point, which has not been reached in the use of this solvent ratio. As shown in the Fig. 3, the trend of the TAG content in the use of the n-hexane + oil to methanol feed flowrate at a level of 6:20 was still increasing despite the fluctuation. It means that the peak point which shows the equilibrium condition has not been reached.

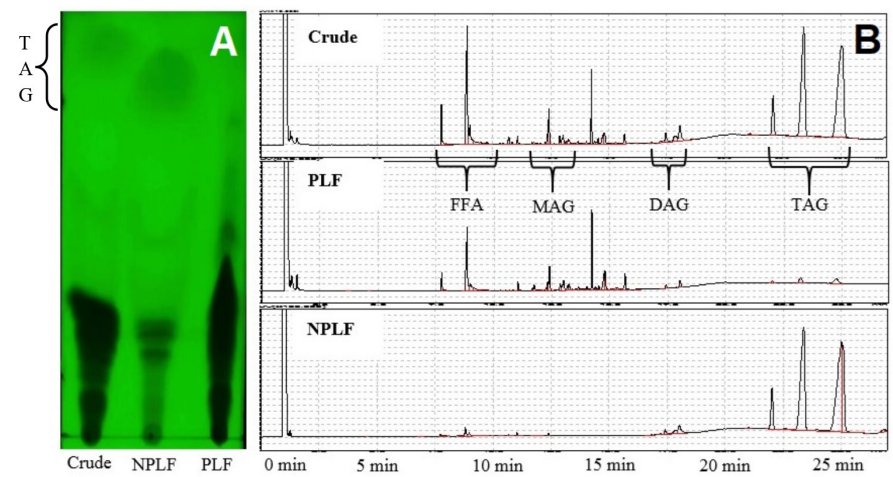

Fig. 2 Results of TLC (A) and HT-GC (B) analyses.
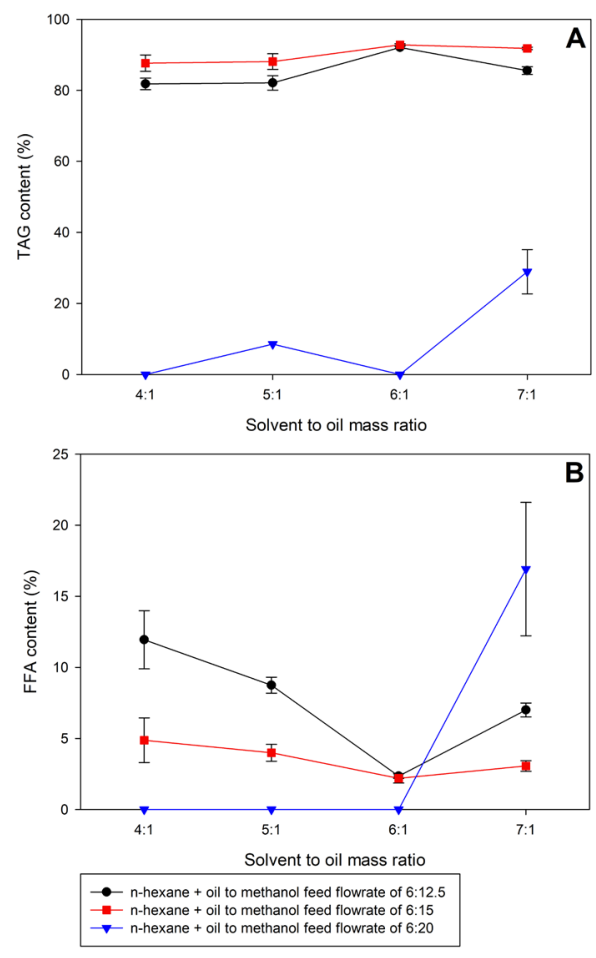

Fig. 3 Effects of solvent to oil mass ratio on TAG (A) and FFA (B) contents.

\section{Effects of $n$-hexane + oil to methanol feed flowrate}

TAG content was investigated increase significantly as n-hexane + oil to methanol feed flowrate was increased from $6: 12.5$ to $6: 15$, and it decreased as this ratio was increased from $6: 15$ to $6: 20$. Then FFA content decreased significantly as n-hexane + oil to methanol feed flowrate was increased from 6:12.5 to 6:20, except for the solvent to oil mass ratio at the level of 7 , which increased as n-hexane + oil to methanol feed flowrate was increased from $6: 15$ to $6: 20$. Therefore, the most significant result was obtained by using an n-hexane + oil to methanol feed flowrate of 6:15 as shown in Fig. 4.

The increase of methanol amount in this solvent counter-current extraction can remove FFA content from the NPLF and leave high levels of the TGA content. However, this condition has the optimum condition which means there is a certain methanol amount can remove the FFA content. The use of higher conditions than the optimum condition can reduce the ability of methanol in removing the FFA content. This is because the higher methanol amount can increase the polarity interaction between methanol and n-hexane as the initial solvent. The high polarity interaction makes a few methanol amounts cannot be separated from the mixture of n-hexane which causes lower FFA content removal. Because of the lover FFA content removal, the amount of the TGA content decreases after the use of the certain methanol amount as shown in the use of the n-hexane + oil to methanol feed flowrate from $6: 15$ to $6: 20$. 
In the use of the n-hexane + oil to methanol feed flowrate of $6: 20$ at the use of a solvent to oil mass ratio of 7:1, the FFA content is higher than the other conditions because of the use of the highest methanol amount. It proves the statement that a few methanol amounts cannot be separated from $n$-hexane because of the polarity interaction between both of solvents.

\section{Effects of combined factors toward NPLF results at the raffinate and each sample points}

This study hypothesized that three most significant combined factors of solvent to oil mass ratio and n-hexane + oil to methanol feed flowrate were 6 and 6:15, 7 and 6:15, and 7 and 6:20, respectively. In these combined factors, the results of six sample points were investigated. The highest content of TAG and the lowest content of FFA for the combined factor of 6 and $6: 15$ were $92.85 \%$ and $2.19 \%$, respectively, which were obtained at the upper zone as NPLF of raffinate as shown in Table 1 and 2. The highest content of TAG and the lowest content of FFA for the combined factor of 7 and 6:15 were $91.83 \%$ and $3.06 \%$, respectively, which were obtained at the upper zone as NPLF of raffinate as shown in Table 1 and 2. Then, the highest content of TAG and the lowest content of FFA for the combined factor of 7 and $6: 20$ were $92.72 \%$ and $3.01 \%$, which were obtained at the $4^{\text {th }}$ sample point or the $\mathrm{H} 4$ (at height of $87.5 \mathrm{~cm}$ ), respectively as shown in Table 1 and 2. After the $4^{\text {th }}$ sample point, the contents of TAG and FFA are unchanged significantly so that the $4^{\text {th }}$ sample point can be concluded as the optimum height for this combined factor. Table 2 proves that the combined factors affect the height of the column. The increase of the used solvent as shown in the combined factors decreases the height of the column. The use of more solvent increases the mass transfer of polar lipid fraction to methanol because of the different polar lipid concentration in the n-hexane and methanol solvent as the driving force. It causes the target of low polar lipid fraction in NPLF oil is quickly achieved in the lower zone.

As shown in Table 1, the most optimum results were obtained by using a combined factor of 6 and $6: 15$ which produces $74.79 \%$ yield of NPLF oil with $92.85 \%$ content of TAG and $2.19 \%$ content of FFA. This result proves that the NPLF oil is suitable for biodiesel feedstock with high TGA content and low enough FFA content. The yield of NPLF oil by using this method is also adequately high, hence it is profitable to be applied. The result of this study can be compared to batchwise solvent extraction by Aparamarta et al. (2016). Crude $C$. inophyllum seed oil contained $78.30 \%$ of TAG, $5.35 \%$ of DAG, 2.75 $\%$ of MAG, $8.51 \%$ of FFA, and $5.09 \%$ others, while the NPLF contained $98.53 \%$ of TAG, $0.35 \%$ of FFA, and $59.57 \%$ oil yield. While this study exhibits fairly similar outcomes compared to the previous study, this method is proven to be more efficient and more suitable for industrial scale application.
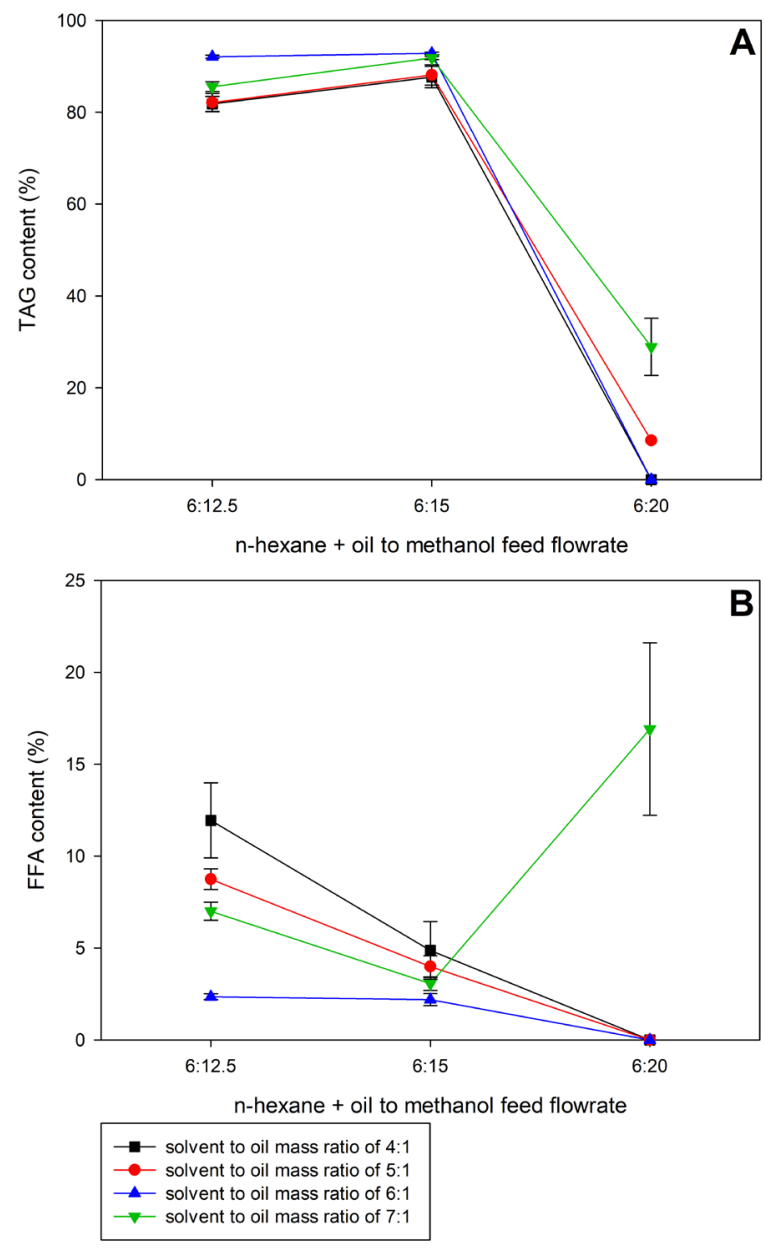

Fig. 4 Effects of $n$-hexane + oil to methanol feed flowrate on TAG $(A)$ and FFA (B) contents.

Table 1 Experimental design and results of continuous countercurrent extraction.

\begin{tabular}{|c|c|c|c|c|c|c|c|c|}
\hline \multirow{2}{*}{$\begin{array}{c}\text { n-Hexane + } \\
\text { crude oil } \\
\text { flowrate (L/h) }\end{array}$} & \multirow{2}{*}{$\begin{array}{c}\text { Methanol } \\
\text { flowrate } \\
\text { (L/h) }\end{array}$} & \multirow{2}{*}{$\begin{array}{l}\text { Solvent to } \\
\text { oil mass } \\
\text { ratio }\end{array}$} & \multicolumn{5}{|c|}{ Contents (\%) } & \multirow{2}{*}{$\begin{array}{c}\text { Yield of } \\
\text { NPLF oil (\%) }\end{array}$} \\
\hline & & & TAG & DAG & MAG & FFA & Others & \\
\hline 6 & 12.5 & 4 & $81.83 \pm 1.63$ & $3.18 \pm 0.65$ & $1.08 \pm 0.21$ & $11.94 \pm 2.04$ & $1.97 \pm 1.28$ & $63.88 \pm 11.56$ \\
\hline 6 & 12.5 & 5 & $82.13 \pm 2.04$ & $5.55 \pm 0.04$ & $0.40 \pm 0.12$ & $8.74 \pm 056$ & $3.18 \pm 1.56$ & $48.51 \pm 27.15$ \\
\hline 6 & 12.5 & 6 & $92.11 \pm 0.34$ & $3.69 \pm 0.22$ & $0.22 \pm 0.03$ & $2.35 \pm 0.16$ & $1.64 \pm 0.06$ & $87.43 \pm 9.07$ \\
\hline 6 & 12.5 & 7 & $85.59 \pm 1.08$ & $4.22 \pm 0.19$ & $0.45 \pm 0.03$ & $7.00 \pm 0.49$ & $2.75 \pm 0.37$ & $55.69 \pm 5.61$ \\
\hline 6 & 15 & 4 & $87.68 \pm 2.30$ & $5.28 \pm 0.32$ & $0.36 \pm 0.01$ & $4.87 \pm 1.57$ & $1.80 \pm 1.03$ & $84.70 \pm 7.67$ \\
\hline 6 & 15 & 5 & $88.12 \pm 2.20$ & $7.43 \pm 2.54$ & $0.29 \pm 0.02$ & $3.99 \pm 0.59$ & $1.57 \pm 2.21$ & $64.51 \pm 2.93$ \\
\hline 6 & 15 & 6 & $92.85 \pm 0.28$ & $3.89 \pm 0.21$ & $0.00 \pm 0.00$ & $2.19 \pm 0.33$ & $1.07 \pm 0.28$ & $74.79 \pm 3.34$ \\
\hline 6 & 15 & 7 & $91.83 \pm 0.35$ & $3.17 \pm 0.12$ & $1.71 \pm 1.95$ & $3.06 \pm 0.37$ & $0.75 \pm 1.06$ & $74.01 \pm 8.65$ \\
\hline 6 & 20 & 4 & n.d. & n.d. & n.d. & n.d. & 100.00 & n.d. \\
\hline 6 & 20 & 5 & $8.56 \pm 0.00$ & $6.06 \pm 0.00$ & $0.00 \pm 0.00$ & $0.00 \pm 0.00$ & $8.37 \pm 0.00$ & n.d. \\
\hline 6 & 20 & 6 & n.d. & n.d. & n.d. & n.d. & 100.00 & n.d. \\
\hline 6 & 20 & 7 & $28.93 \pm 6.22$ & $8.13 \pm 2.49$ & $2.75 \pm 0.53$ & $1.91 \pm 4.69$ & $43.28 \pm 7.88$ & n.d. \\
\hline \multicolumn{3}{|c|}{ batch-wise solvent extraction } & $98.53 \pm 0.97$ & $0.42 \pm 0.30$ & $0.06 \pm 0.03$ & $0.35 \pm 0.20$ & $0.64 \pm 0.44$ & n.d. \\
\hline
\end{tabular}


Table 2 TAG and FFA contents (in \%) of significant combined factors at sample points.

\begin{tabular}{|c|c|c|c|c|c|c|c|c|c|c|c|c|}
\hline \multirow{2}{*}{$\begin{array}{l}\text { Combined } \\
\text { factors }\end{array}$} & \multicolumn{2}{|c|}{$H 1^{a}$} & \multicolumn{2}{|c|}{$\mathrm{H} 2$} & \multicolumn{2}{|c|}{ H3 } & \multicolumn{2}{|c|}{ H4 } & \multicolumn{2}{|c|}{ H5 } & \multicolumn{2}{|c|}{ H6 } \\
\hline & TAG & FFA & TAG & FFA & TAG & FFA & TAG & FFA & TAG & FFA & TAG & FFA \\
\hline 6 and $6: 15$ & 1.88 & 49.87 & 3.66 & 58.54 & 4.78 & 64.19 & 4.78 & 71.03 & 46.59 & 39.35 & 77.02 & 13.20 \\
\hline 7 and $6: 15$ & 8.77 & 37.94 & 10.25 & 37.17 & 12.30 & 59.44 & 49.63 & 26.00 & 21.65 & 29.30 & 26.33 & 37.53 \\
\hline 7 and $6: 20$ & 42.41 & 34.21 & 45.60 & 31.65 & 50.97 & 28.30 & 92.72 & 3.01 & 92.61 & 3.17 & 92.50 & 2.95 \\
\hline
\end{tabular}

${ }^{a}$ The height of sample points, $1^{\text {st }}$ to $6^{\text {th }}$, respectively

\section{CONCLUSION}

Separation and purification of TAG from crude C. inophyllum seed oil were successfully carried out by using a continuous countercurrent extraction process. The most important factors of this study were solvent to oil mass ratio and (n-hexane + oil) to methanol feed flowrate which the optimum combined factor of 6 and 6:15 was recommended to be used for obtaining the suitable biodiesel feedstock. The high content of TAG was obtained as the non-polar lipid fraction. This study is possible to be the most effective and efficient method to process $C$. inophyllum seed oil become suitable for biodiesel feedstock.

\section{ACKNOWLEDGEMENT}

The authors would like to thank the Directorate General of Resources for Science, Technology and Higher Education, Ministry of Research, Technology and Higher Education of Republic Indonesia for the financial support $(716 / \mathrm{PKS} / \mathrm{ITS} / 2019)$ provided to fund this research.

\section{REFERENCES}

Aparamarta H. W., Saputra, T., Claratika, A., Ju, Y. H., Gunawan, S. 2016. Separation and purification of triacylglycerols from nyamplung (Calophyllum inophyllum) oil by batchwise solvent extraction. Ind. Eng. Chem. Re. 55, 3113-3119.

Atabani, A. E., Silitonga, A. S., Ong, H. C., Mahlia, T. M. I., Masjuki, H. H. 2013. Non-edible vegetable oils : A critical evaluation of oil extraction, fatty acid compositions, biodiesel production, characteristics, engine performance and emissions production. Renew. Sust. Energy Rev. 18, 211 245 .
Gunawan, S., Aparamarta, H. W., Ju, Y. H. 2018. Utilization of Calophyllum inophyllum seed oil. In N. K. D. Hong (Ed.), Seed oil: Production, uses and benefits. New York: Nova Science Publishers, Inc., 111-144.

Gunawan, S., Kasim, N. S., Ju, Y. H. 2008. Separation and Purification of squalene from soybean oil deodorizer distillate. Sep. Purif. Technol. 60, $128-135$.

Gunawan, S., Vali, S. R., Ju, Y. H. 2006. Purification and identification of rice bran oil fatty acid steryl and wax esters. J. Am. Oil Chem. Soc. 83, 1-8.

Hathurusingha, S., Ashwath, N., Midmore, D. 2011. Periodic variation in kernel oil content and fatty acid profiles of Calophyllum innophyllm L.: A potential biodiesel feedstock in Australia. Biomass. Bioenerg. 35, 3448-3452.

Kiser, R. W., Johnson, G. D., Shetlar, M. D. 1955. Solubilities of various hydrocarbons in methanol. J. Chem. Eng. Data. 6, 338-341.

Ling, K. H., Kian, C. T., Hoon, T. C. 2009. A guide to medicinal plants: An illustrated, scientific and medicinal approach. Singapore: World Scientific Publishing Co. Pte. Ltd.

Rauber, J. 2004. Design practice for packed liquid-liquid extraction columns. Switzerland: Sulzer Chemtech Ltd.

Sadek, P. 2002. The HLPC Solvent Guide. United States of America: Wiley of Interscience.

Seader, J. D., Henley, E. J. 2006. Separation Process Principles (Second Ed.). United State of America: John Wiley \& Sons, Inc.

Singh, S. P., Singh, D. 2010. Biodiesel production through the use of different sources and characterization of oils and their esters as the substitute of diesel : A review. Renew. Sust. Energ. Rev. 14, 200-216.

Susanto, D. F., Aparamarta, H. W., Widjaja, A., Gunawan, S. 2017. Identification of phytochemical compounds in Calophyllum inophyllum leaves. Asian Pac. J. Trop. Biomed. 7, 773-781.

Tan, P. W., Tan, C. P., Ho, C. W. 2011. Antioxidant properties : Effects of solidto-solvent ratio on antioxidant compounds and capacities of Pegaga (Centella asiatica). Int. Food Res. J. 562, 557-562.

Treybal, R. E. 1951. Liquid Extraction (First Ed.). New York: McGraw-Hill Book Company, Inc. 